\title{
Active Interruption of Motor Combustion for Ammonium-Perchlorate Composite Propellant
}

\author{
By Yosuke MEICHIN ${ }^{1)}$ and Masafumi TANAKA ${ }^{1)}$ \\ 1) National Defense Academy, Yokosuka, Japan \\ (Received June 30th, 2017)
}

\begin{abstract}
Most of solid propellants have difficulty in controlling magnitude of their thrust or stopping their operation arbitrarily. Some solid propellants show a unique property of self-quenching in intermediate pressure range. This property could be utilized for the realization of actively controlled solid propellant rocket motor. However, little is known about the mechanism of this self-quenching phenomenon. In this paper, a simulation model of this phenomenon is developed and the simulation results are compared with the experiment results to determine the mechanism of this self-quenching phenomenon. The simulation results are in good agreement with the experiment results by assuming self-quenching phenomenon has stochastic nature and by selecting proper parameters.
\end{abstract}

Key Words: Solid Propellant, Rocket Motor, Combustion Interruption, Modeling \& Simulation

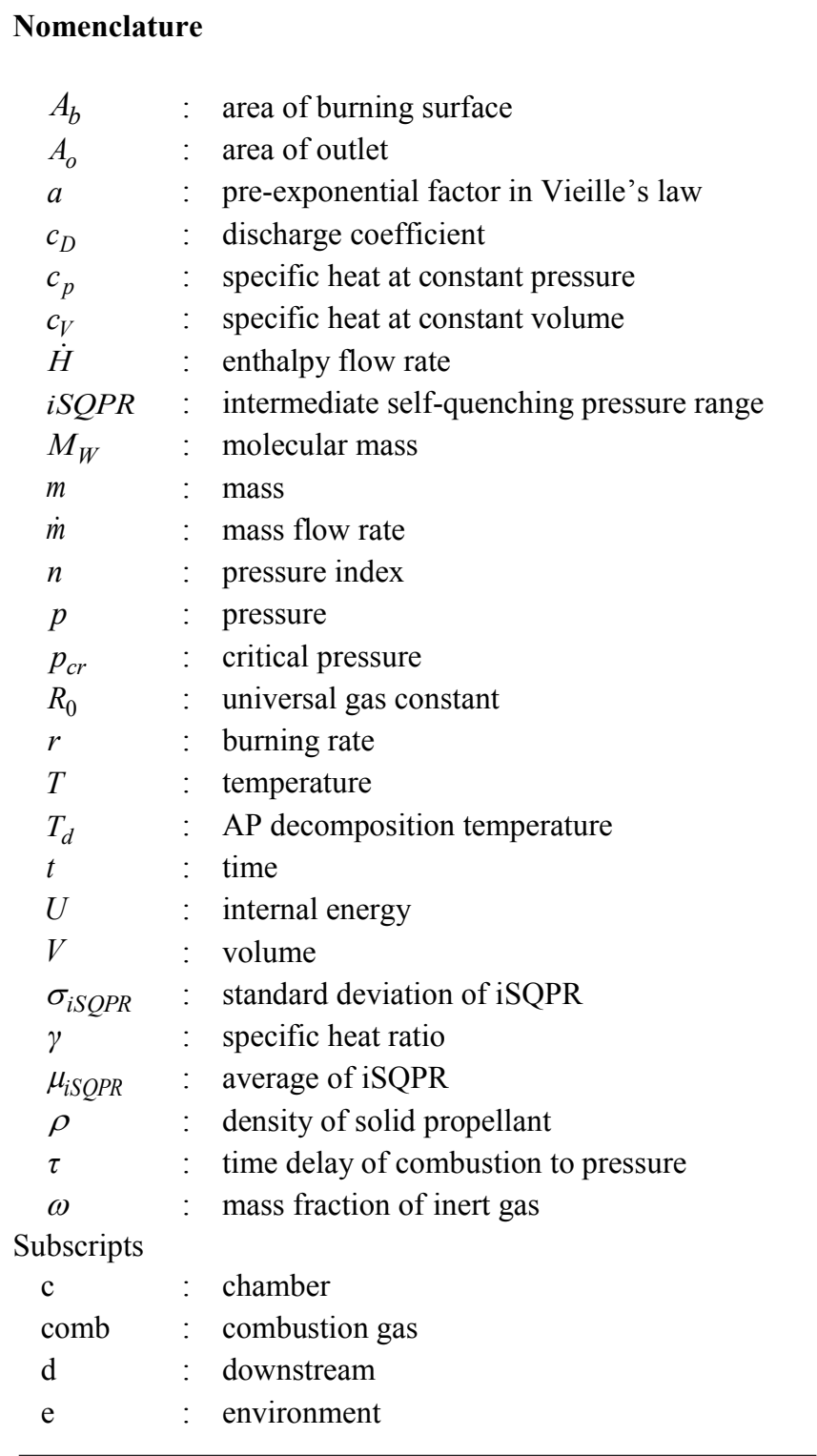

$\begin{array}{lll}\mathrm{f} & : & \text { flame } \\ \mathrm{g} & : \text { generation } \\ \text { High } & : \text { high mode } \\ \mathrm{i} & : \text { input } \\ \text { ign } & : \text { ignition of solid propellant } \\ \text { inert } & : \text { inert gas } \\ \text { Low } & : \text { lower limit or low mode } \\ \mathrm{n} & : \text { time step } \\ \mathrm{o} & : \text { output } \\ \mathrm{s} & : \text { gas storage } \\ \text { Up } & : \text { upper limit } \\ \text { vc } & : \text { start of valve closing } \\ \text { vo1 } & : \text { start of first stage valve opening } \\ \text { vo2 } & : \text { start of second stage valve opening } \\ 0 & : \text { initial }\end{array}$

\section{Introduction}

Solid propellant rocket motors have been used in many propulsion systems for their reliability and storability. While solid propellant rocket motors have these merits, they have difficulty in controlling magnitude of their thrust or stopping operation arbitrarily. As a result, most solid propellant rocket motors have been operated under their pre-programmed thrusttime properties, and this has been limiting the utilization of solid propellant rocket motors.

On the other hand, some ammonium perchlorate (AP) and hydroxyl-terminated polybutadiene (HTPB) based composite propellants show a unique combustion characteristic of selfquenching in some $\mathrm{MPa}$ intermediate pressure range. ${ }^{1)}$ Figure 1 schematically shows the relations between chamber pressure $\mathrm{p}_{\mathrm{c}}$ and mass flow rates of such propellants burned in a choked chamber. In Fig. 1, two curves, mass generation rate curve and mass discharge rate curve, are drawn and two equilibrium points of mass generation rate and mass discharge rate appear. 
One equilibrium point at lower $\mathrm{p}_{\mathrm{c}}$ is "low mode" of combustion and the other equilibrium point at higher $p_{c}$ is "high mode" of combustion. $^{2,3)}$ A pressure range where mass generation rate becomes 0 is called "intermediate self-quenching pressure range", or iSQPR, which has lower limit iSQPR Low $_{\text {and }}$ upper limit iSQPR $\mathrm{R}_{\mathrm{Up}}$. At low mode, oscillatory combustion, repeats of stop and restart of combustion, or mass generation, is achieved. In contrast, stable combustion is achieved at high mode.

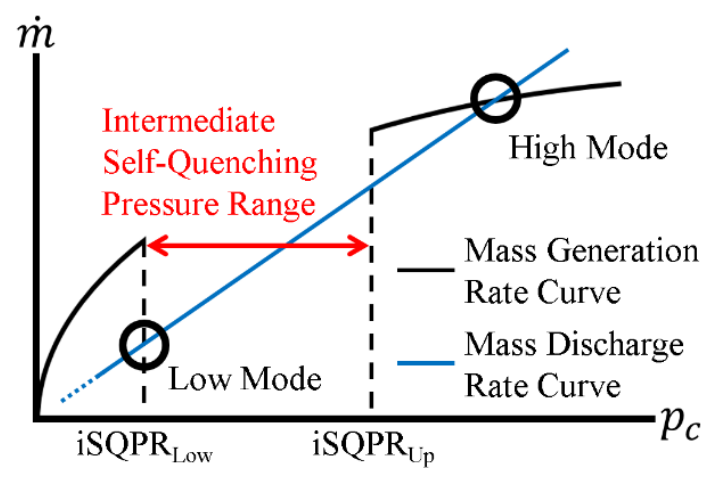

Fig. 1. Mass generation rate curve and mass discharge rate curve for selfquenching solid propellant, and "low mode" and "high mode" of combustion.

This self-quenching property could be utilized for the realization of active thrust controlled solid rocket motors. Tanaka et al. demonstrated an active combustion interruption method of a solid propellant rocket motor with inert gas injection. ${ }^{4}$ In their proposed method, a solid propellant was burned at low mode, inert gas was injected into a combustion chamber to hold $\mathrm{p}_{\mathrm{c}}$ in iSQPR, and combustion interruption was accomplished.

However, little is known about the detailed mechanism of this self-quenching phenomenon. In this paper, our objective is to get better knowledge about this phenomenon. To accomplish this objective, we did combustion interruption experiments of solid propellant with inert gas injection, developed a simulation model, and compared the simulation results and the experiment results to validate the developed model.

\section{Experiments}

Four experiments (Exp. $1 \sim 4$ ) were conducted. Table 1 shows conditions of these experiments. Nitrogen $\left(\mathrm{N}_{2}\right)$ and Helium (He) were used as inert gas. Exp. 1 and 2 were inert gas injection experiments without combustion, and Exp. 3 and 4 were combustion interruption experiments with inert gas injection. In the following subsections, details of a solid propellant, an experiment apparatus, experiment procedures, and experiment results are discussed.

Table 1. Conditions of experiments.

\begin{tabular}{ccccccc}
\hline Exp. & Inert gas & Combustion & $\begin{array}{c}\mathrm{p}_{\mathrm{s} 0} \\
(\mathrm{MPa})\end{array}$ & $\begin{array}{c}\mathrm{p}_{\mathrm{c} 0} \\
(\mathrm{MPa})\end{array}$ & $\begin{array}{c}\mathrm{T}_{\mathrm{s} 0} \\
(\mathrm{~K})\end{array}$ & $\begin{array}{c}\mathrm{T}_{\mathrm{c} 0} \\
(\mathrm{~K})\end{array}$ \\
\hline 1 & Nitrogen & No & 9.17 & 0.10 & 307 & 300 \\
2 & Helium & No & 9.60 & 0.10 & 300 & 300 \\
3 & Nitrogen & Yes & 11.6 & 0.10 & 302 & 306 \\
4 & Helium & Yes & 11.6 & 0.10 & 301 & 301 \\
\hline
\end{tabular}

\subsection{Solid propellant}

The solid propellant used for these experiments contained $73 \%$ AP oxidizer and $27 \%$ fuel binder in total grain mass and was not metalized. The crystalline AP particles had a unimodal distribution in diameter of $15 \mu \mathrm{m}$. The fuel binder consisted of $73.1 \%$ HTPB, $19.8 \%$ dioctyl adipate (DOA), and $7.1 \%$ isophorone diisocyanate (IPDI) in total binder mass. Table 2 shows other parameters of this propellant. Pre-exponential factors and pressure indexes were determined from results of strand burner experiments. Specific impulse was calculated under conditions of ratio of chamber pressure to environment pressure 40, optimum expansion, and frozen flow using CEA. ${ }^{5}$

The end-burning grain was $77 \mathrm{~mm}$ in diameter and was partitioned into 21 sectors by squarely crossed Bakelite plates as shown in Fig. 2. Previous studies indicate the partitioning is necessary to extinguish combustion with inert gas injection.

Table 2. Parameters of solid propellant.

\begin{tabular}{cccc}
\hline Name & Symbol & Value & Unit \\
\hline Pre-exponential factor (Low mode) & $\mathrm{a}_{\text {Low }}$ & 3.05 & $\mathrm{~mm} / \mathrm{s} \cdot \mathrm{MPa}^{\mathrm{n}}$ \\
Pressure index (Low mode) & $\mathrm{n}_{\text {Low }}$ & 0.49 & - \\
Pre-exponential factor (High mode) & $\mathrm{a}_{\text {High }}$ & 2.44 & $\mathrm{~mm} / \mathrm{s} \cdot \mathrm{MPa}^{\mathrm{n}}$ \\
Pressure index (High mode) & $\mathrm{n}_{\text {High }}$ & 0.66 & - \\
Specific impulse & $\mathrm{I}_{\mathrm{sp}}$ & 196 & $\mathrm{~s}$ \\
\hline
\end{tabular}

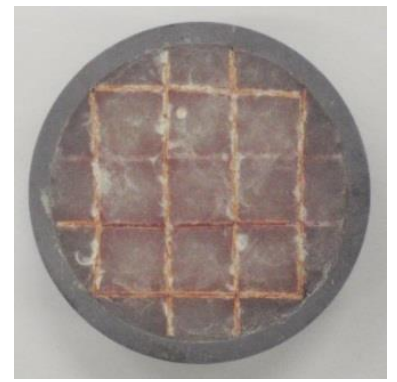

Fig. 2. Partitioned solid propellant grain.

\subsection{Experiment apparatus}

Figure 3 shows our apparatus for combustion interruption experiment of solid propellant with inert gas injection and Table 3 shows parameters of this apparatus.

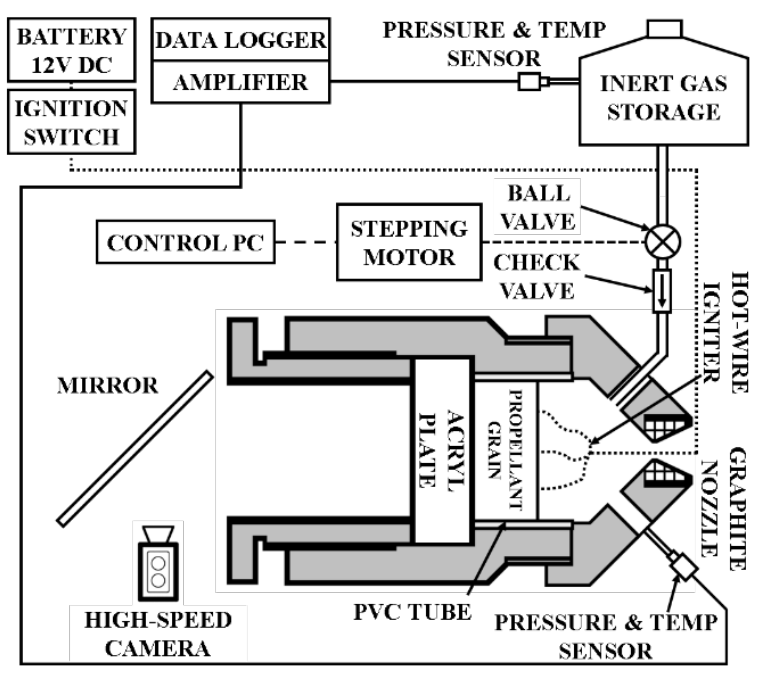

Fig. 3. Apparatus for combustion interruption experiment. 
Table 3. Parameters of experiment apparatus.

\begin{tabular}{cccc}
\hline Name & Symbol & Value & Unit \\
\hline Gas storage volume & $\mathrm{V}_{\mathrm{s}}$ & 4.60 & $\ell$ \\
Chamber volume (before ignition) & $\mathrm{V}_{\mathrm{c}}$ & 430 & $\mathrm{~m} \ell$ \\
Gas injection inlet diameter & $\mathrm{D}_{\mathrm{i}}$ & 4.0 & $\mathrm{~mm}$ \\
Graphite nozzle throat diameter & $\mathrm{D}_{\mathrm{t}}$ & 3.5 & $\mathrm{~mm}$ \\
\hline
\end{tabular}

The combustion chamber contains the solid propellant grain and equips a gas injection inlet, sensors for pressure and temperature measurement, and a graphite nozzle for gas exhaust. The temperature sensor is type R (Platinum Rhodium $-13 \%$ / Platinum) thermocouple. A hot-wire igniter powered by a $12 \mathrm{~V} \mathrm{DC}$ battery ignites the solid propellant grain with support of small boron/potassium nitrate pellets. The chamber head end is made of transparent acryl plate. This transparent acryl plate and translucent propellant grain allow to observe light emitting burning surface from the back of the burning surface with a high-speed camera. This high-speed camera takes a picture every $1 \mathrm{~ms}$.

The gas injection system is composed of a gas storage, a ball valve, a check valve, a stepping motor, and a control PC. The ball valve controls gas flow between the gas storage and the chamber. The check valve prevents high temperature combustion gas from flowing into the gas storage. The stepping motor drives the ball valve based on a pre-programmed sequence stored in the control PC. This valve controlling sequence features a 2-stage valve opening scheme to prevent $p_{c}$ from going beyond iSQPR and combustion from reaching high mode, while it allows the simulation model to be simplified. The gas storage equips the same pressure and temperature sensors as the chamber equips. These sensors are connected to an amplifier, and a data logger records data from the amplifier.

\subsection{Experiment procedures}

All experiments had almost the same procedures except ignition of a solid propellant was done or not. Detailed procedures are described below.

1) Load the solid propellant grain with the hot-wire igniter, and attach the sensors and the gas injection inlet in the chamber.

2) Pressurize the gas storage to specified pressure with inert gas.

3) Ignite the solid propellant (Exp. 3 and 4 only).

4) Manually judge whether combustion reached low mode or not, based on value of $\mathrm{p}_{\mathrm{c}}$ (Exp. 3 and 4 only).

5) Manually trigger gas injection.

\subsection{Experiment results}

\subsubsection{Inert gas injection without combustion}

Figures 4 and 5 show results of Exp. 1 and 2, inert gas injection experiments without combustion, respectively. The time of the start of the first stage valve opening, $t_{\mathrm{vol}}$, is at time origin of both figures. The time of the start of the second stage valve opening, $t_{\mathrm{vo} 2}$, and the time of the start of the valve closing, $\mathrm{t}_{\mathrm{vc}}$, of both figures are at $0.6 \mathrm{~s}$ and $1.6 \mathrm{~s}$, respectively. Environment pressure, $\mathrm{p}_{\mathrm{e}}$, is atmospheric pressure, $0.1 \mathrm{MPa}$. Table 1 shows values of initial gas storage pressure, $\mathrm{p}_{\mathrm{s} 0}$, initial chamber pressure, $\mathrm{p}_{\mathrm{c} 0}$, initial gas storage temperature, $\mathrm{T}_{\mathrm{s} 0}$, and initial chamber temperature, $\mathrm{T}_{\mathrm{c} 0}$.

Both figures clearly show the 2-stage valve opening scheme and steep rises of chamber temperature $T_{c}$ at $t_{\mathrm{vo} 1}$ and $t_{\mathrm{vo} 2}$ and steep fall of $T_{c}$ at $t_{v c}$.

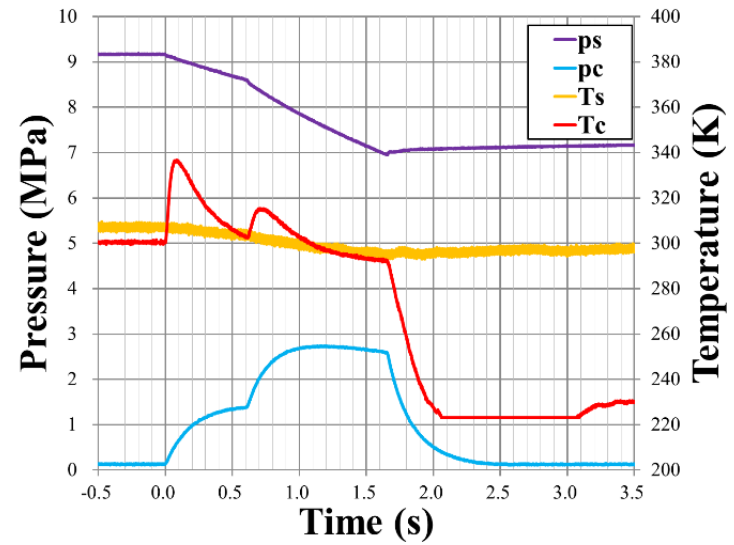

Fig. 4. Histories of pressure and temperature of Exp. 1, $\mathrm{N}_{2}$ injection without combustion.

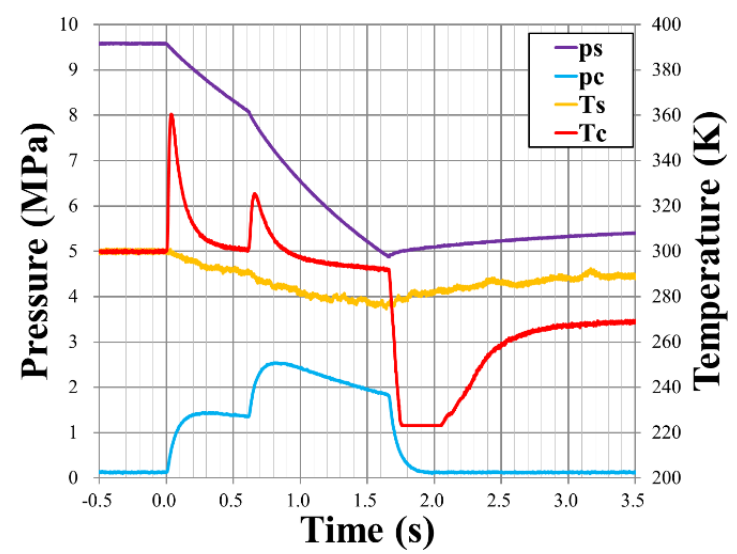

Fig. 5. Histories of pressure and temperature of Exp. 2, He injection without combustion.

\subsubsection{Combustion interruption}

Figures 6 and 7 show results of Exp. 3 and 4, combustion interruption experiments with inert gas injection, respectively. Pictures of burning surface taken with the high-speed camera are also shown in these figures. $t_{\mathrm{vo} 1}$ and $t_{\mathrm{vo} 2}$ of both figures are at $0.0 \mathrm{~s}$ and $0.6 \mathrm{~s}$, respectively. In Exp. 3, the time of the ignition of the solid propellant, $t_{\text {ign, }}$ is at $-2.5 \mathrm{~s}$ and $\mathrm{t}_{\mathrm{vc}}$ is at $2.3 \mathrm{~s}$. In Exp. 4 , $\mathrm{t}_{\mathrm{ign}}$ is at $-2.6 \mathrm{~s}$ and $\mathrm{t}_{\mathrm{vc}}$ is at $1.6 \mathrm{~s}$. $\mathrm{p}_{\mathrm{e}}$ is atmospheric pressure, $0.1 \mathrm{MPa}$. Table 1 shows values of $\mathrm{p}_{\mathrm{s} 0}, \mathrm{p}_{\mathrm{c} 0}, \mathrm{~T}_{\mathrm{s} 0}$, and $\mathrm{T}_{\mathrm{c} 0}$.

Both figures clearly show oscillatory nature of low mode and steep falls of $\mathrm{T}_{\mathrm{c}}$ at $\mathrm{t}_{\mathrm{vo} 1}$ and $\mathrm{t}_{\mathrm{vo} 2}$. Value of iSQPR $\mathrm{Low}_{\text {for this solid }}$ propellant is about $3.0 \mathrm{MPa}$ and this value is consistent with previous studies. Pictures during steep falls of $T_{c}$, not shown here, indicate combustion interruptions were accomplished by gradual decrease of the number of burning sectors, not by simultaneous quenching of all sectors.

Figure 6 shows $p_{c}$ of Exp. 3 was kept well above iSQPR Low during entire valve opening period, a good condition for combustion interruption. This is confirmed by a picture indicating combustion interruption was completely accomplished soon after $t_{\mathrm{vo} 2}$. In contrast, Fig. 7 shows $\mathrm{p}_{\mathrm{c}}$ of Exp.

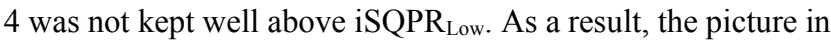
the middle shows one sector of the partitioned grain continued burning even after $t_{\mathrm{vo} 2}$. Rapid depressurization at $t_{\mathrm{vc}}$ caused combustion interruption. 


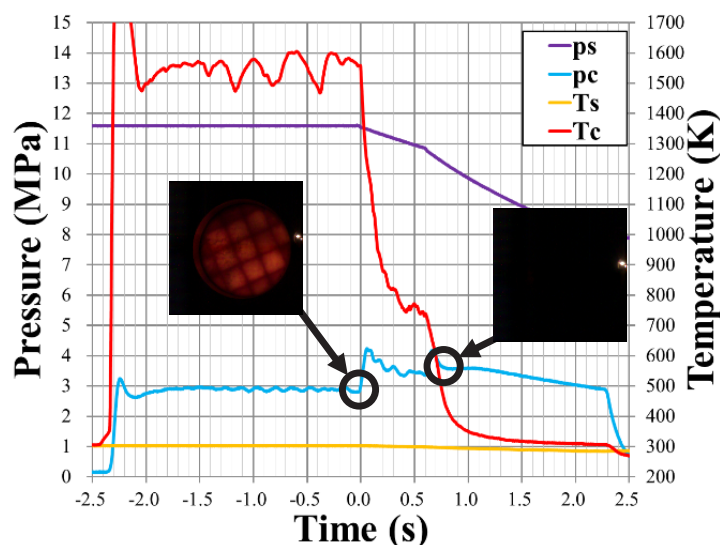

Fig. 6. Histories of pressure and temperature, and pictures of burning surface of Exp. 3, combustion interruption with $\mathrm{N}_{2}$ injection.

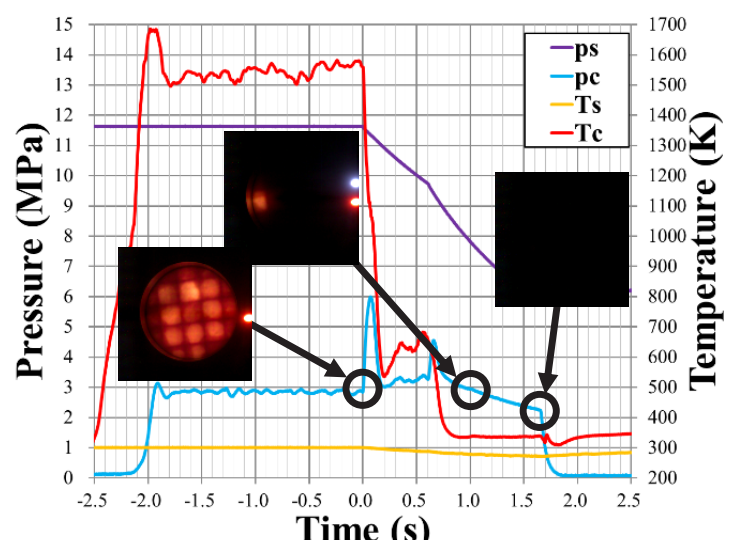

Fig. 7. Histories of pressure and temperature, and pictures of burning surface of Exp. 4, combustion interruption with He injection.

\section{Modeling and Simulations}

In this section, we develop a simulation model of selfquenching phenomenon and perform simulations. Details of this model and these simulations are discussed in the following subsections.

\subsection{Modeling}

Basic assumptions of this model are listed below.

1) Every gas is perfect gas.

2) Every thermodynamic process is isentropic process.

3) Every solid propellant specific parameter such as burning rate characteristic, combustion temperature, and molecular mass of combustion gas, etc. has given value.

This model has 2 routines, namely, the gas phase routine and the burning surface routine. The gas phase routine simulates transfers of mass and energy, and the burning surface routine simulates generations of mass and energy in the chamber.

\subsubsection{Gas phase routine}

Figure 8 shows a schematic diagram of the gas phase routine. The gas phase routine has 3 elements, the gas storage, the chamber, and the environment, and it simulates the transfers of mass and energy between these elements.

The gas storage and the chamber have 5 properties, pressure $p$, volume $\mathrm{V}$, internal energy $\mathrm{U}$, mass $\mathrm{m}$, and temperature $\mathrm{T}$. The environment is a boundary condition of this model and has one property, $\mathrm{p}$, which never changes throughout a simulation.

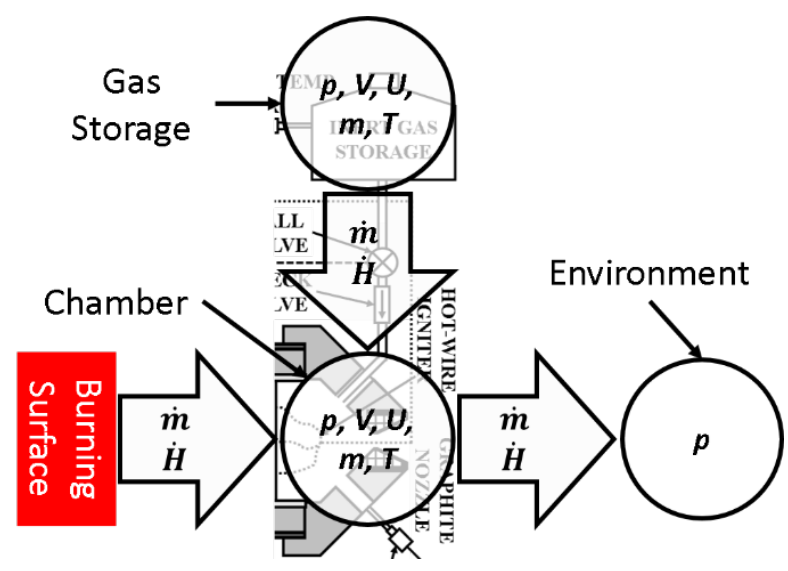

Fig. 8. Schematic diagram of gas phase routine.

In this model, the transfers of mass and energy between the gas storage and the chamber, and, the chamber and the environment are considered first. When considering an element, the gas storage or the chamber, mass flow rate from this element to the downstream element is

$$
\dot{m}=A_{o} \sqrt{\frac{2 \gamma_{n} p_{n}^{2} M_{W, n}}{\left(\gamma_{n}-1\right) R_{0} T_{n}}\left\{\left(\frac{p_{d, n}}{p_{n}}\right)^{\frac{2}{\gamma_{n}}}-\left(\frac{p_{d, n}}{p_{n}}\right)^{\frac{\gamma_{n}+1}{\gamma_{n}}}\right\}},
$$

when pressure of the downstream element $\mathrm{p}_{\mathrm{d}}$ is greater than critical pressure $\mathrm{p}_{\mathrm{cr}}$, or

$$
\dot{m}=A_{o} c_{D} p_{n},
$$

when $\mathrm{p}_{\mathrm{d}}$ is less than $\mathrm{p}_{\mathrm{cr}}$. In these equations, $\mathrm{p}_{\mathrm{cr}}$ and $\mathrm{c}_{\mathrm{D}}$ are

$$
\begin{gathered}
p_{c r}=p_{n}\left(\frac{2}{\gamma_{n}+1}\right)^{\frac{\gamma_{n}}{\gamma_{n}-1}}, \\
c_{D}=\sqrt{\frac{\gamma_{n} M_{W, n}}{R_{0} T_{n}}\left(\frac{2}{\gamma_{n}+1}\right)^{\frac{\gamma_{n}+1}{\gamma_{n}-1}}} .
\end{gathered}
$$

Enthalpy flow rate from this element to the downstream element is

$$
\dot{H}=c_{p, n} \dot{m} T_{n} .
$$

Then, mass, internal energy, temperature, and pressure of this element at next time step are

$$
\begin{gathered}
m_{n+1}=m_{n}+\left(t_{n+1}-t_{n}\right)\left(\dot{m}_{i}+\dot{m}_{g}-\dot{m}_{o}\right), \\
U_{n+1}=U_{n}+\left(t_{n+1}-t_{n}\right)\left(\dot{H}_{i}+\dot{H}_{g}-\dot{H}_{o}\right), \\
T_{n+1}=\frac{U_{n+1}}{c_{V, n+1}\left(\frac{m_{n+1}}{M_{W, n+1}}\right)}, \\
p_{n+1}=\frac{m_{n+1} R_{0} T_{n+1}}{M_{W, n+1} V} .
\end{gathered}
$$

In the chamber, mixing of inert gas and combustion gas can occur. Therefore, changes of gas properties must be considered. Mass fraction of inert gas of this element at next time step is

$$
\omega_{n+1}=\frac{\omega_{n}\left\{m_{n}-\left(t_{n+1}-t_{n}\right) \dot{m}_{o}\right\}+\left(t_{n+1}-t_{n}\right) \dot{m}_{i}}{m_{n+1}} .
$$


Then, specific heat at constant volume, specific heat at constant pressure, molecular mass, and specific heat ratio of this element at next time step are

$$
\begin{gathered}
c_{V, n+1}=\omega_{n+1} c_{V, \text { inert }}+\left(1-\omega_{n+1}\right) c_{V, \text { comb }}, \\
c_{p, n+1}=\omega_{n+1} c_{p, \text { inert }}+\left(1-\omega_{n+1}\right) c_{p, \text { comb }}, \\
M_{W, n+1}=\frac{1}{\frac{\omega_{n+1} m_{n+1}}{M_{W, \text { inert }}}+\frac{\left(1-\omega_{n+1}\right) m_{n+1}}{M_{W, \text { comb }}},} \\
\gamma_{n+1}=\frac{c_{p, n+1}}{c_{V, n+1}} .
\end{gathered}
$$

Gas properties of the other elements never change.

\subsubsection{Burning surface routine}

The burning surface routine simulates the generations of mass and energy from combustion of solid propellant in the chamber and adds generated mass and energy to the chamber element of the gas phase routine.

The burning surface routine has 2 stages. At first stage, burning rate of solid propellant is calculated. And at second stage, mass generation rate and enthalpy generation rate are determined. For details, burning rate is

$$
r=a_{\text {Low }} p_{c}^{n_{\text {Low }}}
$$

when $\mathrm{p}_{\mathrm{c}}$ is less than iSQPR $\mathrm{Low}_{\text {, or }}$

$$
r=a_{H i g h} p_{c}^{n_{H i g h}},
$$

when $\mathrm{p}_{\mathrm{c}}$ is greater than iSQPR $\mathrm{R}_{\mathrm{Up}}$, or otherwise

$$
r=0 \text {. }
$$

Mass generation rate and enthalpy generation rate are

$$
\begin{gathered}
\dot{m}_{g}=\rho r A_{b}, \\
\dot{H}_{g}=\frac{c_{p, c o m b} \dot{m}_{g} T_{f}}{M_{W, \text { comb }}} .
\end{gathered}
$$

The burning surface routine is the key to simulate selfquenching phenomenon. However, little is known about combustion of solid propellant. Therefore, several assumptions are made in this routine. They are listed below.

1) The burning surface is partitioned into 21 sectors, same as the actual solid propellant grain. Each sector has its own values of $A_{b}$ and iSQPR $R_{\text {Low }}$.

2) Sectors are independent each other; $r$ and $i S Q P R_{L o w}$ are calculated at each sector, and no flame propagation exists between sectors.

3) Each sector completely stops the generations of mass and enthalpy when $\mathrm{p}_{\mathrm{c}}$ is in iSQPR.

4) iSQPR $R_{\text {Low }}$ is calculated at every sector and at every time step. It follows a normal distribution with average $\mu_{\mathrm{iSQPR}, \mathrm{Low}}$ and standard deviation $\sigma_{\text {iSQPR,Low, }}$ that is, its value is in range of $\mu_{\text {iSQPR,Low }} \pm \sigma_{\text {iSQPR,Low }}$ with $68 \%$ probability.

5) Value of $p_{c}$ used to judge condition of 3 ) has delay of time $\tau$.

6) Combustion is completely extinguished when $T_{c}$ is less than AP decomposition temperature $\mathrm{T}_{\mathrm{d}}$.

7) Total mass generation rate and enthalpy generation rate are sum of those of each sector.

These assumptions are confirmed by the following experimental observations. The partitioned grain repeats flickering independently in each sector in low mode. Bakelitemade partitioning plates survive motor combustion. The quenched surface is not flat but shows a bumpy aspect. Some statistical approach will be allowed for modeling. Assumption 6) will be backed up through the previous investigation that the average low mode pressure was dependent on the surrounding combustion gas temperature. ${ }^{\text {) }}$

\subsection{Simulations}

The model discussed in Section 3.1 was executed on Microsoft Excel using its macro feature. Four simulations (Sim. $1 \sim 4$ ) were performed. Their results are shown in Section 4. Sim. 1 and 2 are inert gas injection simulations without combustion and correspond to Exp. 1 and 2, respectively. Sim.

\begin{tabular}{|c|c|c|c|}
\hline Name & Symbol & Value & Unit \\
\hline Initial chamber pressure & $\mathrm{p}_{\mathrm{c} 0}$ & 3.0 & $\mathrm{MPa}$ \\
\hline Initial chamber temperature & $\mathrm{T}_{\mathrm{c} 0}$ & 1550 & $\mathrm{~K}$ \\
\hline Flame temperature & $\mathrm{T}_{\mathrm{f}}$ & 1550 & $\mathrm{~K}$ \\
\hline Average of iSQPR Low $_{\text {L }}$ & $\mu_{\mathrm{iSQPR}, \mathrm{Low}}$ & 3.0 & $\mathrm{MPa}$ \\
\hline Standard deviation of iSQPR $\mathrm{Low}_{\mathrm{L}}$ & $\sigma_{\text {iSQPR,Low }}$ & 0.75 & $\mathrm{MPa}$ \\
\hline AP decomposition temperature & $\mathrm{T}_{\mathrm{d}}$ & 513 & $\mathrm{~K}$ \\
\hline Time delay of combustion to pressure & $\tau$ & 50 & $\mathrm{~ms}$ \\
\hline
\end{tabular}
3 and 4 are combustion interruption simulations with inert gas injection and correspond to Exp. 3 and 4, respectively. In every simulation, $\mathrm{p}_{\mathrm{e}}$ was set to atmospheric pressure, $0.1 \mathrm{MPa}$. And $\mathrm{p}_{\mathrm{s} 0}, \mathrm{~T}_{\mathrm{s} 0}, \mathrm{t}_{\mathrm{vo} 1}, \mathrm{t}_{\mathrm{vo} 2}$, and $\mathrm{t}_{\mathrm{vc}}$ were set to be same as the corresponding experiment. $\mathrm{p}_{\mathrm{c} 0}$ and $\mathrm{T}_{\mathrm{c} 0}$ of Sim. 1 and 2 were also set to be same as the corresponding experiments. And $\mathrm{p}_{\mathrm{c} 0}, \mathrm{~T}_{\mathrm{c} 0}$, and other parameters of Sim. 3 and 4 are shown in Table 4.

Table 4. Parameters of combustion interruption simulations.

In this paper, $\mathrm{p}_{\mathrm{c} 0}$ was set to $\mu_{\mathrm{iSQPR}, \mathrm{Low}}$, and $\mu_{\mathrm{iSQPR}, \text { Low }}$ was set to average of $p_{c}$ when combustion occurred in experiments. $T_{c 0}$ was set to $T_{f}$, and $T_{f}$ was set to average of $T_{c}$ when combustion occurred in experiments. And $\mathrm{T}_{\mathrm{d}}$ was set to crystal transition temperature of AP. Values of $\sigma_{\mathrm{iSQPR}, \text { Low }}$ and $\tau$ were selected to fit the simulation results to the experiment results.

\section{Comparison of Experiment and Simulation}

In this section, the simulation results are shown and are compared with the corresponding experiment results to validate the developed model and to get better knowledge of selfquenching phenomenon of solid propellant.

\subsection{Inert gas injection without combustion situation}

Figures 9 and 10 show results of Sim. 1 and 2, and compare them with the results of Exp. 1 and 2, the inert gas injection without combustion situation, respectively. Both figures show the simulation results are in good agreement with the experiment results. Pressure curves are well matched, while temperature curves are less matched, especially for the $\mathrm{He}$ injection situation.

The reason for this discrepancy is inexistence of thermal conduction between gas and surroundings in this model. In experiments, the temperature curves recovered to environment temperature quickly, indicating thermal conduction between gas and surroundings has non-negligible effect on temperature.

From these comparisons, it is proved that the gas phase routine of this model has enough accuracy for simulations of self-quenching phenomenon. 


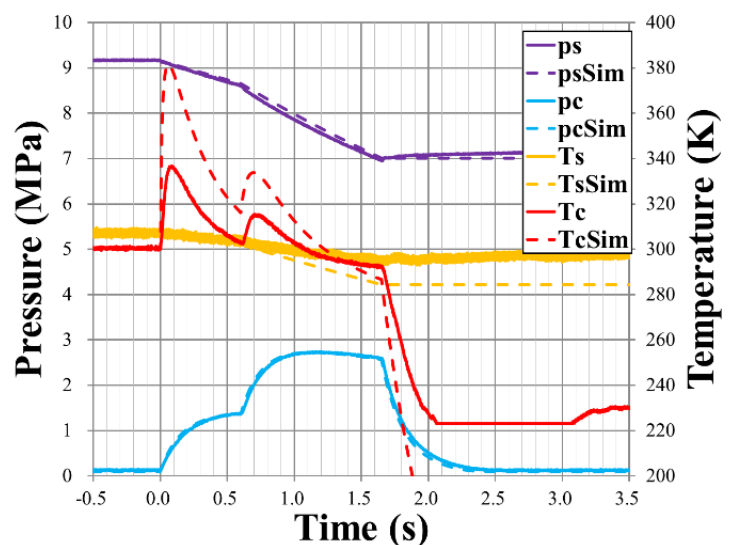

Fig. 9. Comparison of pressure and temperature histories of Sim. 1 (broken lines) and Exp. 1 (solid lines), $\mathrm{N}_{2}$ injection without combustion.

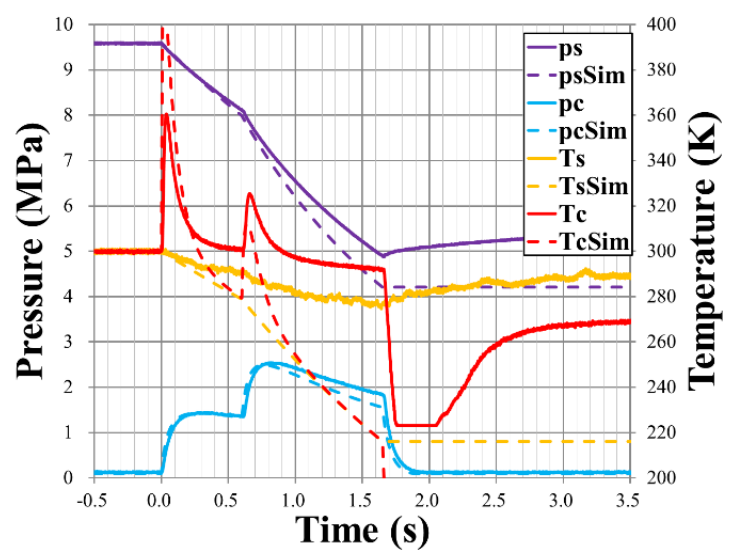

Fig. 10. Comparison of pressure and temperature histories of Sim. 2 (broken lines) and Exp. 2 (solid lines), He injection without combustion.

\subsection{Combustion interruption situation}

Figures 11 and 12 show results of Sim. 3 and 4, and compare them with the results of Exp. 3 and 4, the combustion interruption with inert gas injection situation, respectively. Figure 11 shows the result of Sim. 3 is in good agreement with that of Exp. 3. In contrast, Fig. 12 shows the result of Sim. 4 is quite different from that of Exp. 4, especially for $\mathrm{p}_{\mathrm{c}}$ and $\mathrm{T}_{\mathrm{c}}$.

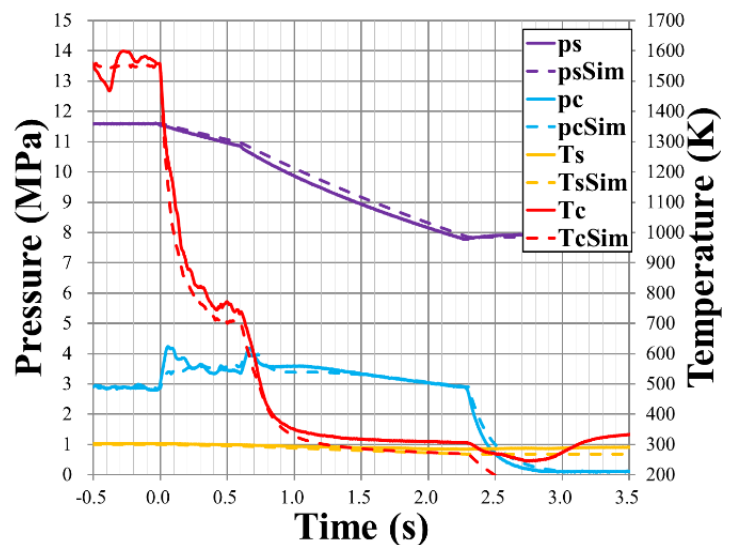

Fig. 11. Comparison of pressure and temperature histories of Sim. 3 (broken lines) and Exp. 3 (solid lines), combustion interruption with $\mathrm{N}_{2}$ injection.

The reason for this discrepancy is use of $T_{c}$, temperature of gas, in this model to judge whether AP decomposition stops or not, that is, combustion is terminated or not. Temperature of gas, especially $\mathrm{He}$, falls faster than temperature of solid propellant itself. Therefore, combustion interruption of Sim. 4 was accomplished sooner than Exp. 4.

Combustion interruptions of experiments and simulations were caused by gradual decrease of the number of the burning sectors, not by simultaneous quenching of all sectors. This tendency of the simulation results comes from the assumption of stochastic nature of burning surface. This implies some stochastic processes play an important role in self-quenching phenomenon of solid propellant.

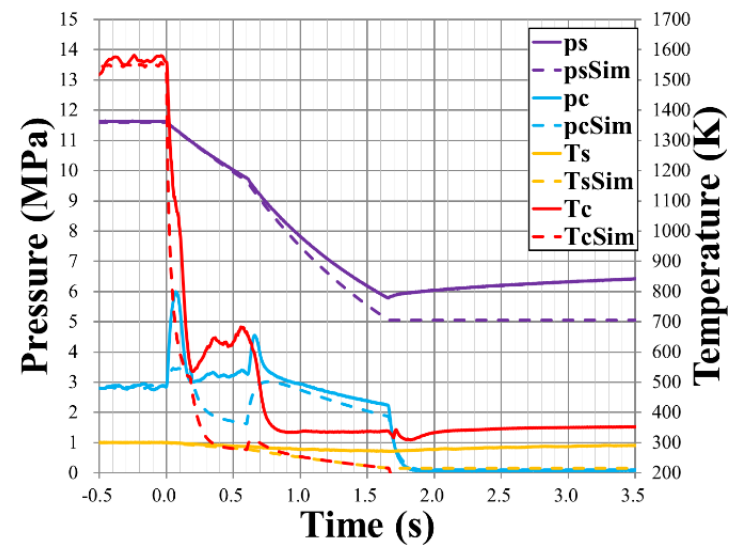

Fig. 12. Comparison of pressure and temperature histories of Sim. 4 (broken lines) and Exp. 4(solid lines), combustion interruption with $\mathrm{He}$ injection.

\section{Conclusion}

In this paper, combustion interruption experiments were conducted and a simulation model was developed to get better knowledge about the self-quenching phenomenon of solid propellant.

The simulation results are compared with the experimental results. Most simulation results are in good agreement with the experimental results with the assumption of stochastic nature of burning surface. This implies some stochastic processes play an important role in this phenomenon.

However, there is difference between the simulation result and the experiment result in the combustion interruption with He injection situation. This discrepancy comes from lack of details of a condensed phase of a solid propellant in our simulation model. And there is a possibility of stochastic nature of burning surface comes from the condensed phase. Therefore, we will continue development of this simulation model to include the condensed phase of the solid propellant. 
Trans. JSASS Aerospace Tech. Japan Vol. 17, No. 3 (2019)

\section{References}

1) Chakravarthy, S. R., Price, E. W., and Sigman, R. K.: Binder Melt Flow Effects in the Combustion of AP - HC Composite Solid Propellants, AIAA Paper 1995-2710, 1995.

2) Tanaka, M., Gaspard, G., and Urakawa, K.: Combustion Characteristic-Based Active Thrust Modulation of a Solid Rocket Motor, Trans. JSASS, Aerospace Tech Japan, 8, ists27(2010), pp. Pa_1-Pa_5.

3) Tanaka, M. and Yokomine, Y.: Active Dual Thrust Modulation of a Solid Rocket Motor, Trans. JSASS, Aerospace Tech Japan, 10, ists28(2012), pp. Pa_25-Pa_30.
4) Tanaka, M. and Shibasawa, G.: Active Interruption of SolidPropellant Combustion in a Choked Chamber, AIAA Paper 20154177, 2015.

5) Gordon, S. and McBride, B. J.: Computer Program for Calculation of Complex Chemical Equilibrium Compositions and Applications, NASA Reference Publication 1311, 1994

https://www.grc.nasa.gov/www/CEAWeb/ (accessed September 4, 2017).

6) Tanaka, M. and Seki, Y.: Automatic Pressure Adjustment Mechanism of a Motor Applying an Intermittent Burning Characteristic of Solid Propellants, 38th International Annual Conference of ICT, Karlsruhe, Germany, 2007, 10_1-10_12. 